\title{
Effectiveness Of Structured Teaching Program On Knowledge and Fear of Alzheimer's Disease in Cognitively Intact Older Adults
}

\author{
Eman Baleegh Meawad ${ }^{1}$, Neamit Ibrahim Elemam Elashri ${ }^{1}$, Abdel-Hady El- \\ Gilany ${ }^{2} \&$ Raefa Refaat Alam ${ }^{1}$ \\ ${ }^{1}$ Assistant. Professor of Gerontological Nursing, Faculty of Nursing, Mansoura University, Egypt \\ ${ }^{2}$ Professor of Public Health, Faculty of Medicine, Mansoura University, Egypt
}

\section{Abstract}

Background: Alzheimer's disease (AD) is considered one of the major public health problem throughout the world especialy among older adults. Fear of developing AD has become a topic of interest. So it's important to raise awareness about AD through assessment of elders' knowledge regarding $\mathrm{AD}$ aiming to improve diagnosis and treatment modalities, inorder to reduce stigma and improve community support in different clinical care settings.Aim: To measure the effectiveness of structured teaching program on knowledge and fear of Alzheimer's disease in cognitively intact older adults. Methods: A quasi-experimental, pre and post intervention research design was implemented.The study was conducted at the Geriatric Outpatient Clinic of the Specialized Medical Hospital, Mansoura University, Egypt. A purposive sample of 54 elderly of both sexes attending the above-mentioned setting according to inclusion and exclusion criteria. Tools: Five tools were used for data collection; Elderly People's Demographic and Clinical Data, MiniMental State Examination (MMSE), Self-rated Health status Scale, The Alzheimer's Disease Knowledge Scale (ADKS), and The Fear of Alzheimer's Disease Scale (FADS). Results: Both ADKS and FADS overall scores showed significant increase after the program implementation (17.62 \pm 4.07 and $41.61 \pm 24.70$ vs.19.18 \pm 3.59 and $48.05 \pm 26.66$; respectively). This improvement favours young elderly female, single, and illiterate elderly who have poor health status, haven't information about the disease or didn't provide any care for Alzheimer's patients, and worried from affection of the disease. A statistically significant positive correlation was found between ADKS total mean score of studied elders and their fear from AD (FADS) before and after the implementation of the structured teaching program. Conclusion: The intervention program improved knowledge but increased fear of AD in elderly. Recommendations: Planning training program to older adults about the other measures to reduce dementia worry such as cognitive behavioral therapy (CBT) or counseling services, development of awareness campaigns about $\mathrm{AD}$ and dementia directly to the general public, and health care provider to combat the negative stigma associated with the disease.

Key words: Knowledge, Fear, Alzheimer's Disease, Cognitively Intact Older Adults

Received : 25/7/2021

Accepted : 5/8/2021

Published : 1/9/2021

\section{Introduction}

Dementia is a global phenomenon among aging population and it is a common medical condition and a public health issue, mainly for developing countries (1, 2). Approximately 47.5 million people around the world have some type of dementia and about 7.7 million new cases of dementia develop every year estimated by WHO (2015). It is expected also that the 
total number of individuals with dementia is expected to rise to 75.6 million by 2030 and nearly triple to 135.5 million by the end of $2050^{(3)}$. In Egypt, although there are only few reports about the prevalence rates of dementia in general and $\mathrm{AD}$ in particular, it was mentioned that the estimated number of Egyptian persons suffering from dementia in 2013 is about 350000 persons; most of them are elderly ${ }^{(4)}$.

Alzheimer's disease (AD) is the leading cause of dementia and a $4^{\text {th }}$ leading cause of death among older adults after cancer, cardiovascular disease, and stroke ${ }^{(\mathbf{5 , 6})}$. It is a chronic, progressive, and debilitating health condition characterized by the loss of memory, language problems (difficulties in speaking and understanding), and poor problem solving ability, poor cognitive skills, and inability to efficiently perform activities of daily living ${ }^{(\mathbf{7}, \mathbf{8})}$. Consequently, it is currently considered one of the major public health problem throughout the world ${ }^{(9)}$.

"Preclinical AD", or "asymptomatic at risk for AD" is a condition when neuropathological brain changes related to Alzheimer's Disease (AD) start in healthy,

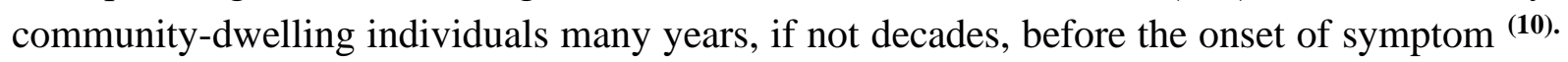
Interventions provided at any moment during the lifespan in such persons would possibly reduce or delay the cognitive changes that ultimately have an effect on a substantial number of seniors worldwide and impair their capacity to live independently ${ }^{(11)}$.

Alzheimer's disease literacy means the individual's knowledge about disease. It involves patients scientific knowledge and understanding of the disease causes, consequences, symptoms, progress, and management ${ }^{(12,13)}$. To tackle the stigma of dementia and open up a better-informed debate about the needs of affected individuals, knowledge levels should be enhanced. Hence abetter-informed public is more likely to challenge alzheimer's disease misconceptions, identify its first signs, and seek early treatment and open up a better-informed debate about the needs of those affected ${ }^{(12)}$.

Moreover, gaining knowledge provides elderly with the opportunity to verbalize their ideas, wishes, fears and get prepared for dealing with their needs and future plans. It also facilitates the identification and use of the available facilities and equipment, early call for help, and effective planning for care before the exacerbation of symptoms. Also it helps families, healthcare providers, and other caregivers effectively cope with AD sufferers' behaviors and relieve the physical and psychological burden of caregiving $(\mathbf{1 4 , 8 )}$. On the other hand, lack of knowledge increase individuals' susceptibility to AD and can lead to symptom exacerbation. Due to the importance of AD and other types of dementia and the significant role of knowledge in coping with them, World Health Organization has considered public education about $\mathrm{AD}$ as one of the most important public health policies that need to be included in national health programs $(\mathbf{8 , 1 5})$.

As Alzheimer's disease develops slowly, many individuals confuse early dementia with age-related deteriorations in cognitive functioning. Individuals may realize that something is wrong but they are too embarrassed, scared, or less knowledgable to discuss it with family members or a doctor. Many studies that queried people age 60 years and older, they found 
that most of the participants were most afraid of developing Alzheimer's disease, followed by cancer, stroke, diabetes, and arthritis $(\mathbf{1 6 , 1 7 , 1 8 )}$. Alzheimer's disease is associated with the most fear and this is due to it's severe emotional impact, insufficient treatment options, fear of rejection by others, and progressive degenerative disease stigma that affect cognition and personality. Moreover, there is a lack of control over the disease process, and it is viewed as a slow and prolonged dying disease ${ }^{(\mathbf{1 9}, \mathbf{2 0}) \text {. }}$

Therefore, the gerontological nurse should encourage elderly people to adhere to lifestyles and behaviors that decrease the risk of the disease and generally educate those individuals adequately about Alzheimer, through developing health education programs constructed on the evidence of what individuals know. Developing and implementing appropriate public education programs can enhance elderly people's knowledge about the disease, reduce its negative consequences, and may lead to decrease anticipatory dementia and the development of anticipatory fear. In addition, having a adequate amount of fear of $\mathrm{AD}$ was found to be a predictor of engaging in behaviors that decrease the risk of the disease $(\mathbf{8 , 2 1 )}$.

\section{Research Aim:}

This study was conducted to measure the effectiveness of structured teaching program on knowledge and fear of Alzheimer's disease in cognitively intact older adults.

\section{Research questions:}

$\mathbf{Q}^{\mathbf{1}}$ : What is the level of knowledge of older adults about Alzheimer's disease?

Q2: What is the degree of fear of older adults from Alzheimer's disease?

$\mathbf{Q}^{2}$ : Does a program about $\mathrm{AD}$ for older adults influence their knowledge and fear of the disease?

$\mathbf{Q}^{3}$ : Is there any relationship between AD knowledge, and fear of the disease?

\section{Materials and Method}

\section{Materials}

I- Design:

Quasi-experimental, pre and post intervention research design was implemented in this study.

\section{II-Setting:}

The study was conducted at the geriatric outpatient clinic of the Specialized Medical Hospital affiliated to Mansoura University Hospital, Mansoura Egypt.

\section{III- Sample size:}

The sample size was calculated online using https://www.openepi.com/SampleSize/. The change in the mean knowledge score is the outcome of interest. A previous study revealed that the pre-intervention mean knowledge score was $19.07 \& \mathrm{SD}_{=} 2.9$ and the postintervention knowledge score was $21.62 \& \mathrm{SD}_{=} 3.73^{\text {(22). }}$ With an alpha error of $5 \%$ and study power or $95 \%$ then the sample size is 45 at least. Twenty percent was added to compensate for dropout during follow-up. thus the final sample size is 54 older adults.

Subjects: A purposive sample of 54 elderly of both sexes attending the above-mentioned setting and fulfilling the following criteria: 
- Aged 60 year and above.

- Able to communicate and willing to participate in the study.

- Normal cognitive ability (score of 24-30).

- No psychiatric illness, neurological diseases, or physical disabilities.

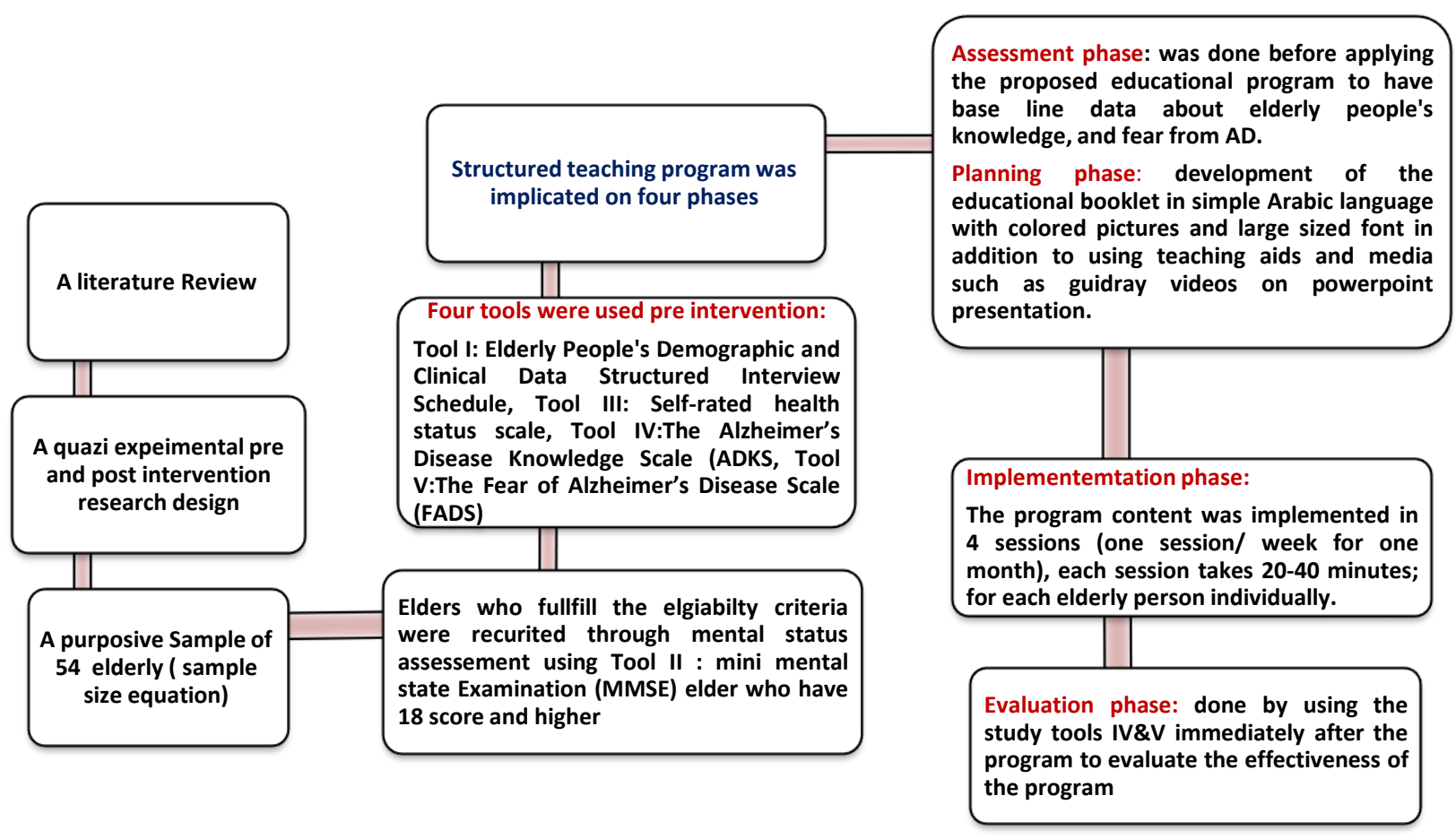

Figure (1): Conceptual research framework of the study

\section{IV- Tools:}

\section{Five tools were used to collect the necessary data:}

Tool I: Elderly People's Demographic and Clinical Data Structured Interview Schedule: It was developed by the researcher after reviewing the related literature, and included two parts:

* Part 1: It included demographic characteristics e.g. age, sex, educational level, marital status, occupation before retirement, income, source of income, residential area, and the living arrangement.

* Part 2: Included medical history; as the presence of chronic illness, duration of disease, medication taken, family health history of Alzheimer's disease, source of their information regarding $\mathrm{AD}$, and previous experience with patients with $\mathrm{AD}$. 
Tool II: Mini- Mental State Examination (MMSE): This scale was developed by Folstien (23). It was translated into the Arabic language by Elokl $2008{ }^{(24),}$ validy and reliability tests were done ( $\left.\mathrm{r}_{=} 0.93\right)$ by Abd El Moniem, 2012 ${ }^{(25)}$. It was designed to assess the cognitive function of the elderly. It composed from 11 items which examine the memory, orientation to time and place, attention, calculation naming, repetition, registration, language, praxis and copying of a design. This was utilized to exclude older adults with a moderate and severe cognitive impairment degrees. The MMSE scale score is 30 points and is classified as follows:

- A score of 24-30 indicates normal cognitive function.

- A score of 18-23 indicates mild cognitive impairment.

- A score of 0-17 indicates severe cognitive impairment.

Tool III: Self-Rated Health Status Scale: It is a broadly used measure of general health. It was assessed by using only one question: -How would you rate your health? Responses were rated from 1 which mean (poor) to 5 that means (excellent) (26). During analysis, Fair and poor responses were grouped and categorized as poor self-rated health, and the other responses were grouped and categorized as good self-rated health.

Tool IV: The Alzheimer's Disease Knowledge Scale (ADKS): It was designed by Carpenter et al, $2009{ }^{(27)}$; it aimed to assess the individual knowledge about Alzheimer's disease The scale was translated into the Arabic language by El-Zeftawy (28). It contains 30 items divided into seven domains. These domains included risk factors of AD, symptoms of $\mathrm{AD}$, course of the disease, assessment , and diagnosis of $\mathrm{AD}$, treatment, and management of $\mathrm{AD}$, impact of $\mathrm{AD}$ on life, and care is given to $\mathrm{AD}$ patients. It comprises 30 -items having true or false answers taking around 5-10 minutes to complete with the resulting score being the number answered correctly, giving a total score with a range of 0 (worst) to 30 (best) with a higher score indicating greater knowledge of Alzheimer's disease. The total score of knowledge was calculated by summing the scores for all items. Possible scores range from 0 to 30 , higher scores indicate a higher knowledge level.

Tool V: The Fear of Alzheimer's Disease Scale (FADS): The FADS is a self-report measure composed from 30-item to assess anticipatory dementia across three different dimensions: older adults' basic and metamemory based fear of developing AD (General Fear) factor 1(Q1-13,Q15-Q17), physical symptoms that older adults experience due to fear of developing AD (Physical symptoms factor 2 (Q18-Q25), and older adults' catastrophic thinking related to fear of developing AD (Catastrophic Attitude factor 3 (Q14,Q26-Q30). Participants indicated their agreement level with the statement using a 5-item likert-type scale ranging from "never," to "always." The FADS has a minimum and maximum score of 0 and 120, respectively with a higher score indicating greater degree of fear from Alzheimer's disease (29). 


\section{Method}

1. An official approval was obtained from the responsible authorities of faculty of nursing Mansoura University.

2. The researcher informed the director of the specialized medical hospital in Mansoura university hospital about the purpose of the study and data collection time to obtain approval to complete the study.

3. The study tool I (elderly people's demographic and clinical data structured interview) was developed by the researcher after thorough review of current literature.

4. The Arabic version of tool IV (the Alzheimer's disease knowledge scale) was used by the researcher. The reliability was assured by means of $r$ coefficient $(r=0.855)$.

5. Tool V (the fear of Alzheimer's disease scale) was translated by the researcher into Arabic language then back-translated to English by two bilingual translators. After that, it was evaluated using test-retest method. This tool was applied on 10 elderly people from an Geriatric outpatient clinic in the General Hospital and reassessed after 2 weeks. The Cronbach's alpha test was done to test the reliability $(r=0.82)$.

6. The validity of the tools was checked by seven experts from the Gerontological nursing field and Psychiatric and Mental health nursing, to check the relevancy, clarity, comprehensiveness, and applicability of the questions then modifications were done, and the final form was used for data collection.

7. A pilot study was carried out on $10 \%$ (6) of the studied participants to test and ascertain clarity and feasibility of the tools, also to estimate the time needed to complete the study tools then the necessary modifications were done accordingly and participants in the pilot were excluded from the study subject.

8. The researcher visited the clinic two days per week (at Sunday and Wednesday) according to the schedule of the geriatric outpatient clinic at a Specialized Medical Hospital.

9. All the elderly person presented in the clinics at Sunday and Wednesday and fulfilling the study criteria were included in the study. The researcher interviewed each participant individually after explaining the study aim.

10. The precautionary practices of infection control were taken as maintaining physical distance, wearing facemask, gloves, and using alcohol aseptic solution for both the researcher and interviewed elders included in the study.

\section{The program was conducted in four phases.}

A. Assessment phase: It was done before applying the proposed educational program to have base line data about elderly people's knowledge, and fear from AD.

B. Planning phase: Included the designing of the educational booklet based on collected data analysis. The booklet was designed after reviewing the most latest literature related to the study; it developed in a simple Arabic language with a large sized font and colored pictures to fit age-related visual changes to improve learning ability of the elderly. The researcher also used teaching aids and media like guidray videos on powerpoint presentation. 
C. Implementation phase: The program implementation: The program content was implemented in 4 sessions (one session/ week for one month), each session takes 20-40 minutes; for each elderly person individually.

i. Session (1): Orientation about the program, common physiological changes in the neurological system, definition, causes and risk factors of $\mathrm{AD}$.

ii. Session (2): Clinical manifestation, stages, and complications of AD.

iii. Session (3): Preventive measures to prevent and delay AD as (eat brainhealthy diet, brain exercises, and relaxation techniques, ......).

iv. Session (4): Nursing intervention, care, and services provided for AD patients.

D. Evaluation phase: It was done by using the study tools IV \& V immediately after the program to determine the effectiveness of the program.

12. The study was conducted over a period of 7 months beginning at December 2020 till the end of June 2021.

\section{Ethical consideration:}

-Ethical approval was obtained from Ethic Committee at Faculty of Nursing-Mansoura University. Official permission was taken from the director of the Specialized Medical Hospital. Oral consent was obtained from elderly persons.

- After a complete clarification of the study aim, participants were informed about the voluntary of their participation and the ability to withdraw from the study at any time. Anonymity, privacy of the participants, and confidentiality of the collected data were guaranteed.

\section{Statistical analysis of the data:}

After collecting the data, variables in each data assessment tool were coded and scored manually prior the entry of data. Descriptive statistics (frequency, mean, percentage and standard deviation) were done for quantitative variables and paired t-test was utilized for pre-post comparison. Spearman's correlation coefficient was used for evaluation between variables of the study. A significant was adopted at $\mathrm{P}$ value $<0.05$ for interpretation of results of significance. High significance was adopted at $\mathrm{P}$ value $<0.01$. Analysis of data was done by using the statistical package of social sciences SPSS.

\section{Results}

Table (1): showed that $57.4 \%$ of the studied elders aged from 60 to 65 years old with Mean \pm SD for the age was $67.74 \pm 5.68$ years, $57.4 \%$ of them are female, $59.3 \%$ were married, $61.1 \%$ were housewives, $63.0 \%$ were illiterate, $75.9 \%$ have adequate monthly income and $75.9 \%$ had no recent work. While About $61.1 \%$ lived with partners and $81.5 \%$ lived in rural areas. 
Table (1): The distribution of older adults according to their socio-demographic and medical characteristics $\left(\mathrm{N}_{\mathbf{n}} \mathbf{5 4}\right)$

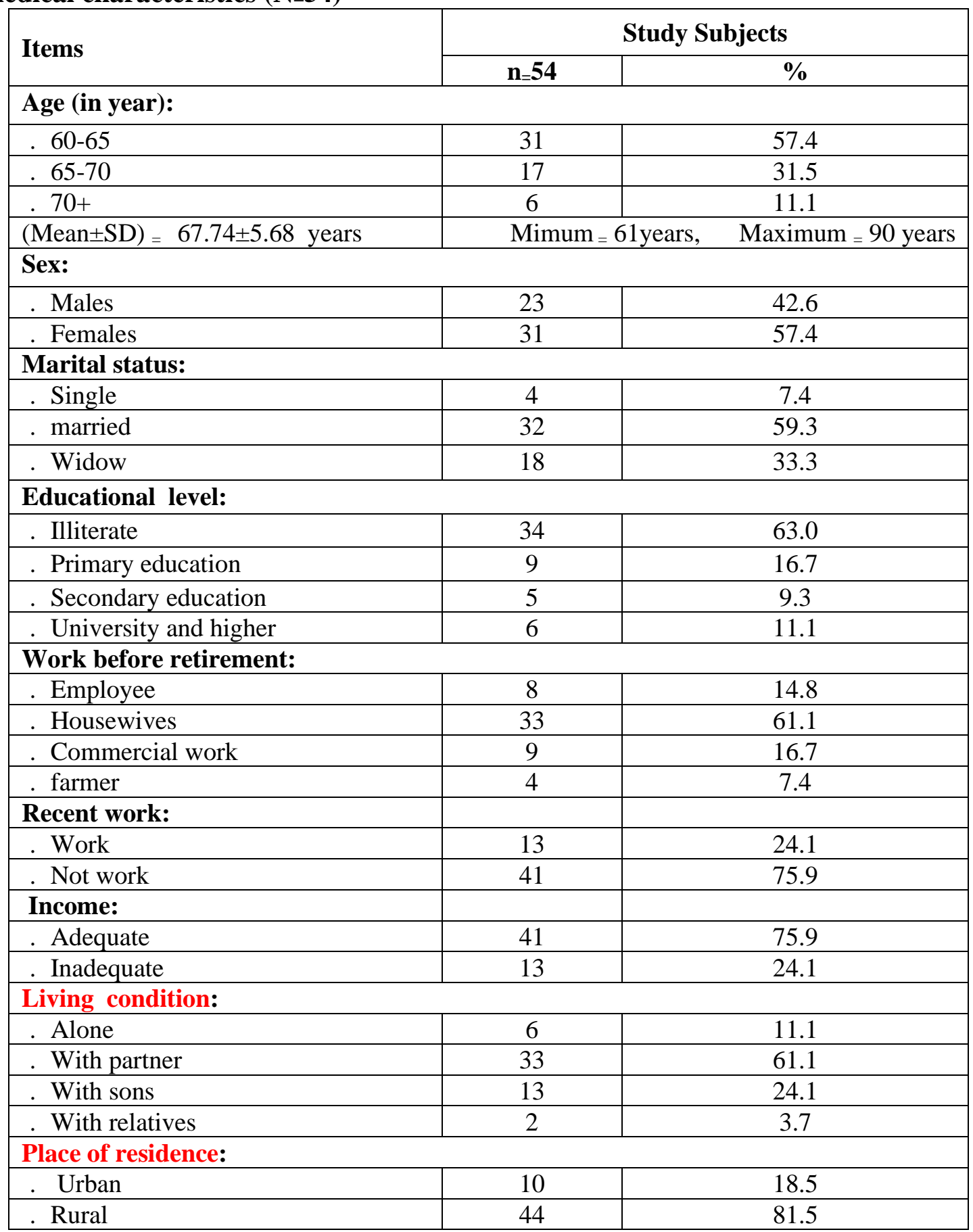

*Significant, at $\mathrm{P} \leq 0.05$, using Chi-Square $\left(\mathrm{X}^{2}\right)$

Table (2): revealed that $77.8 \%$ of elders had chronic diseases, musculoskeletal diseases were prevailing among $51.9 \%$ followed by $46.3 \%$ of them had hypertension, $38.9 \%$ had diabetes mellitus. Regarding the number of chronic diseases, it was observed that $29.6 \%$ had less than three chronic diseases. Additionally, $70.4 \%$ of them rated their general health status as poor condition, furthermore $64.8 \%$ of them reported that they are anxious from affection by Alzheimer's disease (AD). While 98.1\% reported fear from chronic disease, the most afraid condition was heart disease followed by $\mathrm{AD}$, and cancer $(75.9 \%, 74.1 \%$ 
respectively). Nearly $72.2 \%$ of them reported practice unhealthy behavior and $92.6 \%$ reported that they do not have family members affected by AD.

Table (2): The distribution of older adults' according to their health history and their fear from chronic illness

\begin{tabular}{|c|c|c|}
\hline \multirow[t]{2}{*}{ Health history } & \multicolumn{2}{|c|}{ Study subjects } \\
\hline & $n=54$ & $\%$ \\
\hline \multicolumn{3}{|l|}{ History of chronic disease } \\
\hline No & 12 & 22.2 \\
\hline yes & 42 & 77.8 \\
\hline Hypertension & 25 & 46.3 \\
\hline Diabetes Melitus & 21 & 38.9 \\
\hline Heart disease & 5 & 9.3 \\
\hline Musculoskeletal diseases & 28 & 51.9 \\
\hline Respiratory diseases & 8 & 14.8 \\
\hline Nephrology diseases & 1 & 1.9 \\
\hline Liver diseases & 5 & 9.3 \\
\hline \multicolumn{3}{|l|}{ Number of the present chronic diseases } \\
\hline One disease & 10 & 18.5 \\
\hline Two diseases & 16 & 29.6 \\
\hline Three diseases and more & 16 & 29.6 \\
\hline \multicolumn{3}{|l|}{ General health self-rating } \\
\hline Poor & 43 & 79.6 \\
\hline Good & 11 & 20.4 \\
\hline \multicolumn{3}{|l|}{ Fear from chronic diseases } \\
\hline Yes & 53 & 98.1 \\
\hline No & 1 & 1.9 \\
\hline Cardiovascular disease & 41 & 75.9 \\
\hline Alzheimer disease & 40 & 74.1 \\
\hline Cancer disease & 40 & 74.1 \\
\hline Nephrology diseases & 37 & 68.5 \\
\hline Liver diseases & 32 & 59.3 \\
\hline Diabetes Mellitus & 29 & 53.7 \\
\hline Musculoskeletal diseases & 28 & 51.9 \\
\hline \multicolumn{3}{|c|}{ Anxiety from affection of Alzheimer disease } \\
\hline very Anxious & 6 & 11.1 \\
\hline Somewhat anxious & 35 & 64.8 \\
\hline Not at all & 13 & 24.1 \\
\hline \multicolumn{3}{|l|}{ Family members affected by alzheimer } \\
\hline Yes & 4 & 7.4 \\
\hline No & 50 & 92.6 \\
\hline First-degree relation & 2 & 3.7 \\
\hline Second-degree relation & 2 & 3.7 \\
\hline \multicolumn{3}{|l|}{ Practicing unhealthy behaviors } \\
\hline $\mathrm{NO}$ & 15 & 27.8 \\
\hline Yes & 39 & 72.2 \\
\hline . Smoking & 5 & 9.3 \\
\hline . Caffeine consumption & 36 & 66.7 \\
\hline . Polypharmacy without prescription & 10 & 18.5 \\
\hline \multicolumn{3}{|l|}{ Number of medication taken } \\
\hline . No drugs & 17 & 31.5 \\
\hline . Two drugs & 23 & 42.6 \\
\hline . Three drugs and more & 14 & 25.9 \\
\hline
\end{tabular}

*Significant, at $\mathrm{P} \leq 0.05$, using Chi-Square $\left(\mathrm{X}^{2}\right)$ 
Table (3): illustrated that $55.6 \%$ of elderly reported they had previous information about Alzheimer's disease; $48.1 \%$ of them reported mass media as their primary source of information followed by $11.1 \%$ from the internet. Nearly $79.6 \%$ they do not know any person affected by Alzheimer's. While few percent (11.1\%) who provided care for Alzheimer's patients.

Table (3): The distribution of older adults' according to their knowledge sources regarding Alzheimer's disease:

\begin{tabular}{|l|c|c|}
\hline \multirow{2}{*}{ Information about Alzheimer } & \multicolumn{2}{|c|}{ Study subjects } \\
\cline { 2 - 3 } & $\mathbf{n} \mathbf{5 4}$ & $\mathbf{\%}$ \\
\hline Previous information about Alzheimer's & \multicolumn{2}{|c|}{} \\
\hline . Yes & 30 & 55.6 \\
\hline . No & 24 & 44.4 \\
\hline . Newspapers & 4 & 7.4 \\
\hline . Mass media & 26 & 48.1 \\
\hline . Scientific books & 2 & 3.7 \\
\hline . Friends & 4 & 7.4 \\
\hline . Medical staff members & 1 & 1.9 \\
\hline . Alzheimer patient caregivers & 1 & 1.9 \\
\hline . Internet & 6 & 11.1 \\
\hline Knowing any person affected by Alzheimer's & \\
\hline . Yes & 11 & 20.4 \\
\hline . No & 43 & 79.6 \\
\hline Previous caring for Alzheimer's patient & \multicolumn{2}{|l}{} \\
\hline . Yes & 6 & 11.11 \\
\hline . No & 48 & 88.8 \\
\hline
\end{tabular}

Table (4): revealed that ADKS overall mean score was $17.62 \pm 4.07$ before application the program and increased to $19.18 \pm 3.59$ after the programe with a statistically significant improvement ( $\left.p_{=} 0.002\right)$. As for ADKS domains; A statistically significant difference was found in the life impact knowledge domain $\left(\mathrm{p}_{2} 0.009\right)$ followed by treatment knowledge domain $\left(\mathrm{p}_{=}=0.009\right)$, caregiving knowledge domain $\left(\mathrm{p}_{=} 0.000\right)$ and the risk factors knowledge domain $(\mathrm{p}=0.021)$

Table (4): Effect of implementation of the structured teaching program on Alzheimer disease Knowledge (ADKS) domains of the studied elders

\begin{tabular}{|l|c|c|c|}
\hline $\begin{array}{c}\text { Alzheimer disease Knowledge (ADKS) } \\
\text { domains }\end{array}$ & Pre-program & Post-program & Significance \\
\hline -Life impact (Q1.11.28) & $3.16 \pm 1.43$ & $3.74 \pm 1.20$ & $\mathrm{t}=2.723, \mathrm{p}_{=} 0.009$ \\
\hline -Risk factors (Q2.13.18.25.26.27) & $1.72 \pm 0.89$ & $2.07 \pm 0.60$ & $\mathrm{t}=2.385, \mathrm{p}_{=} 0.021$ \\
\hline -Symptoms (Q19.22.23.30) & $1.79 \pm 0.71$ & $1.51 \pm 0.79$ & $\mathrm{t}=1.875, \mathrm{p}_{=} 0.066$ \\
\hline -Treatment (Q9.12.24.29) & $3.22 \pm 1.09$ & $3.64 \pm 1.10$ & $\mathrm{t}=2.700, \mathrm{p}_{=} 0.009$ \\
\hline -Diagnosis (Q4.10.20.21) & $2.79 \pm 0.85$ & $2.79 \pm 0.91$ & $\mathrm{t}=0.000, \mathrm{p}_{=} 1.000$ \\
\hline -Caregiving (Q5.6.7.15.16) & $2.22 \pm 0.83$ & $3.03 \pm 0.72$ & $\mathrm{t}=6.282, \mathrm{p}_{=} 0.000$ \\
\hline -Course of the diseases (Q3.8.14) & $2.70 \pm 1.07$ & $2.37 \pm 0.99$ & $\mathrm{t}=1.670, \mathrm{p}_{=} 0.101$ \\
\hline -Overall score (Q1-30) & $17.62 \pm 4.07$ & $19.18 \pm 3.59$ & $\mathrm{t}=3.307, \mathrm{p}_{=} 0.002$ \\
\hline
\end{tabular}


Table (5): noted that FADS overall mean score was $41.61 \pm 24.70$ before the structured teaching program and it increased to $48.05 \pm 26.66$ after the program with strong statistically significant difference $\left(\mathrm{p}_{=} 0.014\right)$. Regarding increase in fear domains there was a statitstically significant difference in the general fear domain $\left(\mathrm{p}_{=}=0.001\right)$ and symptoms domain $\left(\mathrm{p}_{=} 0.005\right)$, and there was a decrease in the catastrophic attitude domain but without any significant difference $\left(\mathrm{p}_{=} 0.353\right)$.

Table (5): ): Effect of implementation of the structured teaching program on fear from Alzheimer disease (FADS) of the studied elders

\begin{tabular}{|l|c|c|c|}
\hline Fear from Alzheimer (FADS) & $\begin{array}{c}\text { Pre- } \\
\text { program }\end{array}$ & $\begin{array}{c}\text { Post- } \\
\text { program }\end{array}$ & Significance \\
\hline -General fear (factor1) (Q1- & 21.09 & 25.79 & $\mathrm{t}=3.429$, \\
13,Q15-Q17) & \pm 14.63 & \pm 13.95 & $\mathrm{p}=0.001$ \\
\hline & & & \\
-Symptoms (factor 2) (Q18-Q25) & \pm .53 & 12.42 & $\mathrm{t}=2.936$, \\
& \pm 7.46 & \pm 10.08 & $\mathrm{p}=0.005$ \\
\hline & 10.98 & 9.83 & $\mathrm{t}=0.937$, \\
-Catastrophic attuide (factor3) & \pm 8.83 & \pm 7.75 & $\mathrm{p}=0.353$ \\
(Q14.Q26-30) & & & \\
\hline & & & \\
& 41.61 & 48.05 & $\mathrm{t}=2.553$, \\
-Overall score (Q1-Q30) & \pm 24.70 & \pm 26.66 & $\mathrm{p}=0.014$ \\
& & & \\
\hline
\end{tabular}

Table 6: clarified that a statistically improvement in knowledge score and increase the level of fear among widowed elderly female aged from 60 to less than 65 years old $\left(\mathrm{p}_{=}=0.028\right.$, $\mathrm{p}=0.025, \mathrm{p}_{=} 0.040 ; \mathrm{p}=0.004, \mathrm{p}_{=} 0.017$ respectively), illiterate elderly $\left(\mathrm{p}_{=} 0.010, \mathrm{p}_{=} 0.005\right)$ with adequate income $\left(\mathrm{p}_{=} .002, \mathrm{p}_{=} 0.037\right)$, who living in rural areas $\left(\mathrm{p}_{=} 0.003, \mathrm{p}_{=} 0.013\right)$ elderls with somewhat anxious $\left(p_{=} 0.021, p_{=} 0.026\right)$, who reported poor health self-rating $\left(p_{=}=0.010\right.$, $\left.\mathrm{p}_{=} 0.024\right)$, who afraid from $\mathrm{AD}\left(\mathrm{p}_{=} 0.006, \mathrm{p}_{=} 0.053\right)$ and who didn't provide any care for Alzaheimer's patients $\left(\mathrm{p}_{=} 0.003, \mathrm{p}_{=} 0.004\right)$. 
Table 6: Relation between demographic characteristics and clinical data of the studied elders and their knowledge, and mean score of fear from Alzheimer's before and after implementation of the structured teaching program

\begin{tabular}{|c|c|c|c|c|c|c|c|}
\hline $\begin{array}{l}\text { Demographic and } \\
\text { medical Characteristics }\end{array}$ & $\mathbf{N}$ & \multicolumn{3}{|c|}{$\begin{array}{c}\text { Alzheimer disease Knowledge (ADKS) } \\
(\text { Mean } \pm \text { SD) }\end{array}$} & \multicolumn{3}{|c|}{$\begin{array}{l}\text { Fear from Alzheimer (FADS) } \quad(\text { Mean } \pm \text { SD }) \\
\end{array}$} \\
\hline $\begin{array}{l}\text { Overall score } \\
\text { p- value }\end{array}$ & \multicolumn{2}{|c|}{$17.62 \pm 4.07$} & & $19.18 \pm 3.59$ & 41.61 & 24.70 & $48.05 \pm 26.66$ \\
\hline Age in years & \multicolumn{2}{|r|}{ pretest } & posttest & $\mathbf{P}^{1}$ - value & pretest & posttest & $\mathbf{P}^{2}-$ value \\
\hline $60-$ & 31 & $17.93 \pm 4.30$ & $20.00 \pm 4.04$ & $\mathrm{t}=3.080, \mathrm{p}=0.004$ & $44.35 \pm 25.81$ & $52.12 \pm 27.62$ & $\mathrm{t}=2.540, \mathrm{p}=0.017$ \\
\hline $65-$ & 17 & $17.23 \pm 4.32$ & $18.47 \pm 2.69$ & $\mathrm{t}=1.576, \mathrm{p}=0.135$ & $40.82 \pm 24.93$ & $47.11 \pm 26.68$ & $\mathrm{t}=1.187, \mathrm{p}=0.252$ \\
\hline Male & 23 & $16.30 \pm 2.26$ & $18.00 \pm 2.31$ & $\mathrm{t}=2.284, \mathrm{p}=0.032$ & $34.82 \pm 26.30$ & $40.21 \pm 28.17$ & $\mathrm{t}=0.1 .391, \mathrm{p}=0.178$ \\
\hline Female & 31 & $19.61 \pm 4.82$ & $20.06 \pm 4.12$ & $\mathrm{t}=2.354, \mathrm{p}=0.025$ & $46.64 \pm 22.56$ & $53.87 \pm 24.32$ & $\mathrm{t}=2.142, \mathrm{p}=0.040$ \\
\hline \multicolumn{8}{|l|}{ Marital status } \\
\hline Single & 4 & $14.00 \pm 3.65$ & $19.00 \pm 4.96$ & $\mathrm{t}=3.162, \mathrm{p}=0.051$ & $48.00 \pm 38.53$ & $53.75 \pm 39.55$ & $\mathrm{t}=0.932, \mathrm{p}=0.420$ \\
\hline married & 32 & $18.06 \pm 4.24$ & $19.43 \pm 4.03$ & $\mathrm{t}=2.310, \mathrm{p}=0.028$ & $45.06 \pm 26.15$ & $49.71 \pm 27.96$ & $\mathrm{t}=1.375,0.198$ \\
\hline . Secondary level & 5 & $17.80 \pm 2.68$ & $18.40 \pm 2.70$ & $\mathrm{t}=0.557, \mathrm{p}=0.607$ & $50.40 \pm 27.95$ & $53.60 \pm 36.18$ & $\mathrm{t}=0.500, \mathrm{p}=0.643$ \\
\hline . University level & 6 & $23.33 \pm 4.17$ & $24.83 \pm 5.74$ & $\mathrm{t}=1.145, \mathrm{p}=0.304$ & $59.50 \pm 12.70$ & $57.33 \pm 21.61$ & $\mathrm{t}=0.192, \mathrm{p}=0.855$ \\
\hline \multicolumn{8}{|l|}{ Income } \\
\hline Adequate & 41 & $17.39 \pm 4.21$ & $19.12 \pm 3.58$ & $\mathrm{t}=3.313, \mathrm{p}=.002$ & $40.14 \pm 21.35$ & $46.68 \pm 22.44$ & $\mathrm{t}=2.159, \mathrm{p}=0.037$ \\
\hline Inadequate & 13 & $18.38 \pm 3.66$ & $19.38 \pm 3.75$ & $\mathrm{t}=0.931, \mathrm{p}=0.370$ & $46.23 \pm 33.81$ & $52.38 \pm 37.86$ & $\mathrm{t}=1.361, \mathrm{p}=0.199$ \\
\hline \multicolumn{8}{|l|}{ Place of residence: } \\
\hline Urban & 10 & $16.60 \pm 3.59$ & $18.20 \pm 2.44$ & $\mathrm{t}=1.184, \mathrm{p}=0.267$ & $38.50 \pm 15.80$ & $41.10 \pm 18.68$ & $\mathrm{t}=0.462, \mathrm{p}=0.655$ \\
\hline Rural & 44 & $17.86 \pm 4.17$ & $19.40 \pm 3.79$ & $\mathrm{t}=3.104, \mathrm{p}=0.003$ & $42.31 \pm 26.39$ & $49.63 \pm 28.09$ & $\mathrm{t}=2.582, \mathrm{p}=0.013^{*}$ \\
\hline \multicolumn{8}{|c|}{ Previous information about Alzheimer's } \\
\hline Yes & 30 & $18.10 \pm 4.52$ & $19.86 \pm 4.31$ & $\mathrm{t}=2.023, \mathrm{p}=0.055$ & $43.73 \pm 24.53$ & $52.03 \pm 25.71$ & $\mathrm{t}=1.269, \mathrm{p}=0.217$ \\
\hline . No & 24 & $17.04 \pm 3.44$ & $18.33 \pm 2.21$ & $\mathrm{t}=2.588, \mathrm{p}=0.015$ & $38.95 \pm 25.16$ & $43.08 \pm 27.53$ & $\mathrm{t}=2.220, \mathrm{p}=0.034$ \\
\hline \multicolumn{8}{|c|}{ Fear from Alzheimer's diseases } \\
\hline Yes & 40 & $17.67 \pm 4.22$ & $19.37 \pm 3.32$ & $\mathrm{t}=2.932, \mathrm{p}=0.006$ & $45.45 \pm 26.34$ & $50.92 \pm 27.66$ & $\mathrm{t}=1.997, \mathrm{p}=0.053$ \\
\hline NO & 14 & $17.50 \pm 3.75$ & $18.64 \pm 4.36$ & $\mathrm{t}=1.500, \mathrm{p}=0.158$ & $30.64 \pm 15.15$ & $39.85 \pm 22.47$ & $\mathrm{t}=1.559, \mathrm{p}=0.143$ \\
\hline \multicolumn{8}{|c|}{ Knowing any person affected by Alzheimer } \\
\hline . Yes & 11 & $18.09 \pm 2.87$ & $19.36 \pm 2.01$ & $\mathrm{t}=1.308, \mathrm{p}=0.220$ & $57.18 \pm 20.50$ & $55.81 \pm 28.11$ & $\mathrm{t}=0.384, \mathrm{p}=0.709$ \\
\hline . No & 43 & $17.51 \pm 4.35$ & $19.13 \pm 3.91$ & $\mathrm{t}=3.011, \mathrm{p}=0.004$ & $37.62 \pm 24.28$ & $46.06 \pm 26.25$ & $\mathrm{t}=2.836, \mathrm{p}=0.007$ \\
\hline \multicolumn{8}{|c|}{ Previous caring for Alzheimer patient } \\
\hline . Yes & 6 & $23.33 \pm 4.17$ & $24.83 \pm 5.74$ & $\mathrm{t}=1.145, \mathrm{p}=0.304$ & $59.50 \pm 12.70$ & $57.33 \pm 21.61$ & $\mathrm{t}=0.192, \mathrm{p}=0.855$ \\
\hline . No & 48 & $16.91 \pm 3.49$ & $18.47 \pm 2.54$ & $\mathrm{t}=3.077, \mathrm{p}=0.003$ & $39.37 \pm 24.99$ & $46.89 \pm 27.19$ & $\mathrm{t}=3.029, \mathrm{p}=0.004$ \\
\hline
\end{tabular}

Table 7: showed that a statistically significant positive relation was found between the total mean score of studied elders' AD knowledge (ADKS) and their fear from AD (FADS) before and after the program $\left(\mathrm{p}_{=}=0.004, \mathrm{p}=0.000\right.$ respectively). 
Table 7: Correlation of mean score of Alzheimer disease Knowledge (ADKS) of the studied elders and their mean score of fear from Alzheimer (FADS) before and after implementation of the proposed educational program

\begin{tabular}{|l|c|c|}
\hline \multicolumn{1}{|c|}{ Items } & $\begin{array}{c}\text { Fear from } \\
\text { Alzheimer (FADS) } \\
\text { pre }\end{array}$ & $\begin{array}{c}\text { Fear from } \\
\text { Alzheimer (FADS) } \\
\text { post }\end{array}$ \\
\hline $\begin{array}{l}\text { Alzheimer disease Knowledge } \\
\text { (ADKS) pre: }\end{array}$ & $\mathrm{r}_{=} 0.383^{* *}$ & \\
\hline $\begin{array}{l}\text { Alzheimer disease Knowledge } \\
\text { (ADKS) post : }\end{array}$ & $\mathrm{P}_{2}=0.004$ & \multirow{2}{*}{$\mathrm{r}_{=} 0.460^{* *}$} \\
\hline
\end{tabular}

\section{Discussion}

The negative image of Alzheimer's disease (AD) in the society has a significant effect on treating, caring for and integrating those suffering from the disease and their relatives. This can lead to increase fear of older adults from this disease (30). So the development of targeted educational programs about alzhiemer's for elderly people is important to identify their learning needs and concerns and this could be benefical in decreasing this knowledge gap and fear ${ }^{(31-33)}$.

The results of the current study revealed the majority of studied elders were young old (67.74 \pm 5.68 years) females, married and housewives. This finding is supported by many studies ${ }^{(34,22,8)}$. Other studies contradict this results $(\mathbf{3 5}, \mathbf{3 6})$. As for educational level; our results reported nearly two-thirds of the studied elders were illiterate. Similar finding was founded by El-Masry et al (2018) ${ }^{(\mathbf{3 5})}$ who reported that the majority of their participants held low level of education. This result may be explained by most of the study sample from rural areas. On the contrary side; another study done in Saudi Arabia found that the majority of the participants had a bachelor degree or above ${ }^{(32)}$.

The findings of the present study revealed that more than one-half of sample reported that they had previous information about Alzheimer's disease from mass media followed by the internet. This finding could be justified by most of elderly do not have the skills to use the internet and access the information available through computers because most of them were illiterate. In this regard a study conducted in Egypt by El Masry, et al (2018) $^{(35)}$ founded that the majority of their participants mentioned T.V/Radio as a primary source while healthcare providers (HCPs) were the least reported source.The current finding was comparable to that of another Egyptian study on which reported most of the studied population mentioned TV as the best method to offer public awareness about $\mathrm{AD}{ }^{(36)}$. On the same line Alhazzani et al, (2020) ${ }^{(32)}$ reported that nearly one third of their participants receiving the information from social media and websites, and one quarter get the information from the medical websites.

As for caring of alzheimer's patient the majority of the studied elders reported that they do not cared any family members affected with AD.While few percent of them providing care for Alzheimer patient. Similar finding was reported by a study done in Saudi Arabia (2020) revealed that the majority of the participants had no family history with 
Alzheimer's disease (32). This findining may be attributed by AD disease is viewed as a stigmatisezed issue and most of families refuse to speak about it.

$\mathrm{AD}$ is associted with poor health status and it's one of the principal cause of physical disability, institutionalization, and decreased quality of life among the elderly hence it shortens life expectancy. The majority of the studied elders rated their general health status as poor condition, and they are somewhat anxious from affection by AD. Our finding may be ought to the large number of the sample were young old illiterate female lived in rural areas where as lack of availability of medical services, decrease monthly income, and more comorbidities, also they have general worry on their health status than males because our culture makes women are most likely to express their emotions, as fear and anxiety more than men. Sun et al, (2013) ${ }^{\mathbf{3 7}}$ Cutler et al, (2015) ${ }^{\mathbf{3 8}}$ supported this result which concluded that the old old elders were less worried about AD. Also Roberts et al, (2014) ${ }^{\mathbf{3 9}}$ revealed that individuals at 50-65 age group had a significantly greater odds of reporting worry about $\mathrm{AD}$ than individuals aged 75 years and older. It may be explaned that adults aged 80 years and older may develop a better coping strategies in case of developing AD.

Elderly persons usually experience many chronic illness as heart diseases, hypertension, diabetes mellitus, and cancer which cause high levels of psychological stress, anxiety, depression and poor quality of life so they commonly fear from these chronic illness. The results of the present study reported the most disease they were afraid of it were cardiovascular disease followed by Alzheimer's disease, and cancer respectively. This result is in agreement with survey of individuals aged 60 year and older found that more one third of the participants were most afraid of developing Alzheimer's disease, followed by cancer, stroke, diabetes and arthritis ${ }^{(\mathbf{1 6})}$. Similar finding was reported by Vrinten (2014) $)^{\mathbf{4 0}}$, Cantegreil-Kallen et al, (2012) ${ }^{18}$ \& Harris, (2011) ${ }^{17}$. A possible explanation of these findings due to these disease associated with high mortality rate, severe emotional impact, and few treatment options exist.

A better understanding of AD knowledge among older adults is critical in increasing research participation, designing education programs, and accelerating the prevention and traetment of $\mathrm{AD}{ }^{(41)}$. The current study revealed a statistically significant improvement in ADKS overall mean score after the program implication. This finding assured the valuable effect of our structured teaching program through increase elder knowledge regarding the course of disease, its progression, prevention and management strategies. This is congruent with a previous study done by Carpenter et al, (2011) ${ }^{\mathbf{3 3}}$ showed that such programs have positively affect people's knowledge about AD. The same finding was reported by Scerri et al (2017) ${ }^{\mathbf{2 2}}$ who found that the training program significantly improve their participant knowledge of the AD disease. Another study reported similar results done by Patidar et al, (2019) ${ }^{\mathbf{4 2}}$ showed that the mean post-test knowledge score was higher than the mean pre-test score. This result may be atrributed to fear of the elders from the disease and its complications make them concerned with the information given in the program. 
Moreover; the present study revealed that the improvement was obvious in the life impact knowledge domain followed by the treatment, caregiving, and risk factors knowledge domains respectively. This result is consistent with an Iranian study reported the highest percentage of correct answers was related to the items of the life impact dimension of the scale while the lowest percentage was related to the care giving and the risk factor dimensions respectively ${ }^{(8)}$. In similarity, Alhazzani et al, $\mathbf{2 0 2 0}^{\mathbf{3 2}}$ \& Carpenter et al, $\mathbf{2 0 1 1}^{33}$ reported that their participant were least knowledgeable about risk factors domain. On the opposite side a study done by Scerri et al., (2017) ${ }^{\mathbf{2 2}} \&$ Friedland (2011) ${ }^{\mathbf{4 3}}$ found that the ADKS subscales significantly increase in their knowledge level of AD risk factors and caregiving aspects post-training. This difference may be attributed to the difference in sample culture and educational level where as most of the participants are illiterate so they are concerned with treatment and caregiving domain more than risk factors domain. Fear and pessimism of aging may affect health in anegative manner and even decrease lifespan. Contrarily, a positive perception of aging can increase longevity ${ }^{(\mathbf{4 4})}$. Negative perceptions of aging increase hippocampus atrophy and amyloid plaque, brain changes that are linked with Alzheimer's disease, addititionally fear of individuals with mental diseases are observed in individuals with Alzheimer's disease, including fear of rejection by others and progressive degenerative disease stigma that affects cognition and personality (45).

The present study results found that the FADS overall mean score was increased after the program implication than before it with a strong statistical significance difference. The increase in fear domains was statistically significant in the general fear domain followed by the symptoms domain after the program implication, and there was no significant difference in the level of catastrophic attitude domain. This finding can be justified by an increase information about $\mathrm{AD}$ as aserious disease with few treatment options and their awareness of its complications can arouse their inner feelings about its dangerous effect on their health and evoke their fear. This result in the same line with Kessler (2012) ${ }^{46}$, Cantegreil-Kallen (2012) ${ }^{18}$, and Alzheimer Europe, $(\mathbf{2 0 1 1})^{47}$ who reported that enhancing $\mathrm{AD}$ public awareness has led to raising the fear of having the disease, specially in older adults. Contrarily with this finding Scerri et al., (2017) ${ }^{\mathbf{2 2}}$ \& French (2012) ${ }^{\mathbf{2 9}}$ reported that their participants' perceived fear didn't change after completion of the educational program.

Knowledge and fear of Alzheimer's disease affected with many factors as age, gender, marital status, income, level of education, and health status. As regards to age and gender in relation to knowledge and fear from alzaheimer disease after program implication. These results reported a statistically improvement in knowledge score and increase level of fear among young elderly female aged from 60 to less than 65 years old.This finding can be explained by young elderly female consistuted the large number in the study sample and they still having the ability of retreriving and learning new information than middle or old old and also they responsible for providing care for their family members. Similar finding was stated by a study in Egypt, by El-Masry (2018) ${ }^{\mathbf{3 5}}$, and in Saudi Arabia by Alhazzani, $\mathbf{( 2 0 2 0}^{\mathbf{3 2}}$ who founded that younger age was a significant predictors for better knowledge on ADKS than the older ones and reported significantly higher fear overall. While Howell, $\mathbf{( 2 0 1 6 )}^{\mathbf{4 1}}$ and Jafarjalal, (2017) ${ }^{\mathbf{8}}$ showed higher scores of ADKS, and FADS not associated with age or gender. 
There was a statistically significant increase in knowledge and fear among illiterate elderly were observed in our study. This finding can be justified by the large number of the studied elders were illiterate and havn't any information about Alzheimer or provided care for AD patients before. This in accordance with Alhazzani, (2020) ${ }^{\mathbf{3 2}}$ who asserted that education levels did not show significant difference in their participant AD level of knowledge. Also another study by Scerri et al., (2017) ${ }^{\mathbf{2 2}}$, indicated that perceived fear is elevated as level of education is decreased. This result is opposite to study carried out by ElMasry,(2018) ${ }^{35} \&$ Jafarjalal el al, (2017) $)^{8}$ reported that higher education was significant predictors for better knowledge on ADKS .

With regards to marital status in relation to knowledge and fear; there was a statistically significant improvement in knowledge among single and married elderly while there was a significant increase in fear from AD among widowed. This finding can be explained that widowhood accopamines with loss of partner and caregiver and feeling of lonliness, and absence of social interaction which increase the chance of affecting AD and increase their fear from disease complications. This results inconsistent with a study done by Scerri, (2017) ${ }^{\mathbf{2 2}}$ \& Jafarjalal, (2017) ${ }^{\mathbf{8}}$ founded that AD knowledge was not significantly correlated with any of thesocio-demographic characteristics as marital status.

Moreovor the results of the present study revealed there was a statistically significant increase in knowledge and fear among elderly who reported poor health self-rating. Similar finding was reported by Howell, (2016) ${ }^{41}$ who founded that subjects with poor general health condition scored higher ADKS than those who reported good health. Also, there was a statistically significant increase in knowledge among both elderly with or without previous information,while fear increased significantly among elderly reported no previous information. This in the same line with another study done in Iran reported that knowledge score about $\mathrm{AD}$ in the participants who had previously obtained information was only slightly greater than in the other participants ${ }^{(8)}$.

Meanwhile our study results founded there was a statistical significant increase in knowledge and fear among elders who didn't provide any care for Alzheimer's patients. This in accordance with Scerri, (2017) ${ }^{\mathbf{2 2}}$ who reported that AD knowledge and fear scores were not significantly correlated in elders who having or caring for family members with AD. While Jafarjalal, (2017) ${ }^{\mathbf{8}}$ contradict with this finding where knowledge about Alzheimer's disease was significantly correlated with the participants'experience of caregiving to persons with the disease, and familiarity with such persons. This difference may be attributed to most of our sample didn't have information about AD and have lack of experience about it.

Improving elders' knowledge of AD gives a share in increasing fear from affecting with disease among them. The present study revealed a statistically significant positive relation was found between ADKS total mean score of studied elders and their fear from AD (FADS) before the implementation of the structured teaching program. Elders' fear at pretraining was significantly related to their existing knowledge regarding the disease. Also, a statistically significant increase was found between the total mean score of ADKS and FADS after the implementation of the structured teaching program. The higher the mean 
score of AD knowledge, the more afraid of the studied elders from AD. A similar finding was reported by Scerri, (2017) ${ }^{\mathbf{2 2}}$ who stated there was a significant positive correlation between the ADKS and the FADS scores in the pre-training phase.This in congruent with Kessler et al. (2012) ${ }^{\mathbf{4 6}}$ who stated although the program informed the participants about the possible treatment available, this did not seem to have allayed their concerns. Also the same result was supported by Nelissen, $2015^{48}$ \& Sun et al., $2013^{37}$. This result can be justified by that the greater the knowledge of $\mathrm{AD}$, the more the participants were afraid of being at risk of dementia and its complication, and the information given during the program could have confirmed the fact that dementia is have no cure with limited choice of treatment.

\section{Conclusion:}

A significant increase in ADKS and FADS overall mean score after the program implication with a strong statistical significance in the favour of young elderly female, single, and illiterate elderly who have poor health status, havn't information about the disease or didn't provide any care for Alzheimer's patients, and worried from affection of the disease. Also there was statistically significant positive relation was found between ADKS total mean score of studied elders and their fear from AD (FADS) before and after the implementation of the structured teaching program.

\section{Recommendation:}

The following recommendations are suggested:

- Development of training program to elders about the other measures to reduce dementia worry such as cognitive behavioral therapy (CBT) or counseling services.

- Distribution of developed structured teaching program booklet to most of elders in different setting to enhance their knowledge abot Alzaheimer disease and decrease their concerns

- Development of awareness campaigns about $\mathrm{AD}$ and dementia directed to the general public, and health care provider to combat the negative stigma associated with the disease.

\section{Acknowledgements}

The researchers are thankful to all elders attending geriatric out patients' clinics who participated in this study; also they appreciate help provided by the directors affiliated to outpatient clinic in conduction of the study.

\section{References}

1. César KG, Brucki SM, Takada LT, Nascimento LF, Gomes CM, Almeida MC et al. (2016) Prevalence of cognitive impairment without dementia and dementia in Tremembé, Brazil. Alzheimer Dis Assoc Disord. Jul-Sep; 30(3):264-71. https://doi.org/10.1097/WAD.0000000000000122. 
2. Amado DK, Brucki SM. (2018). Knowledge about Alzheimer's disease in the Brazilian population. Arq Neuropsiquiatr; 76(11):775-782.

3. World Health Organization. (2015). Number of people over 60 years set to double by 2050; major societal changes required. Retrieved from http://www.who.int/mediacentre/news/releases/2015/ older-persons-day/en

4. World Health Organization. Dementia: a public health priority. World Health Organization. 2012.

5. James BD, Leurgans SE, Hebert LE, Scherr PA, Yaffe K, Bennett DA. (2014). Contribution of Alzheimer disease to mortality in the United States. Neurology.; 82(12):1045-1050.

6. Prince M, Albanese E, Guerchet M.(2014). World Alzheimer Report 2014.; 1-97.

7. Alzheimer's Association (2015). Alzheimer's disease Facts and Figures. Alzheimer's \& Dementia: The Journal of the Alzheimer's Association.; 11(3): 32 \& 332.

8. Jafarjalal E, Haghani H, Carpenter B, Sajady M, Farahaninia M. (2017). Knowledge about Alzheimer's disease among individuals going to neighborhood houses in northern regions of Tehran, Iran. Arvand Journal of Health \& Medical Sciences Vol. 2, No. 2, 59-69. doi: 10.22631/ajhms.2017.88718.1017.

9. Emilsson UM (2011). The staff's view on dementia and the care in three cultures: A qualitative study in France, Portugal and Sweden. Dementia; 11(1): 31-47.

10. Sperling R, Mormino E, Johnson K. (2014). The evolution of preclinical Alzheimer's disease: implications for prevention trials. Neuron;84:608-622.

11. Smith AD, Yaffe K. (2014). Dementia (including Alzheimer's disease) can be prevented: statement supported by international experts. J Alzheimers Dis;38:699703.

12. Cahill S, Pierce M, Werner P, Darley A, Bobersky A ( 2015). A systematic review of the public's knowledge and understanding of Alzheimer's disease and dementia. Alzheimer Disease \& Associated Disorders; 29(3): 255-275

13. Mukadam N, Cooper C, Livingston G. (2011). A systematic review of ethnicity and pathways to care in dementia. Int J Geriatr Psychiatry; 26: 12-20.

14. Lüdecke D, Knesebeck O, Kofahl C.(2015). Public knowledge about Dementia in Germany-Results of a population survey. International Journal of Public Health.; 61(1): 9-16.

15. Nguyen PT, Nguyen N, Vo K, Ho S, Nguyen J, Woo B KP. (2016). Knowledge of dementia among Vietnamese American immigrants. Asian Journal of Psychiatry.; 20: $340-9$.

16. Alzheimer's Association (2014). Alzheimer's disease facts and figures. Alzheimer's \& Dementia, 10, e47-e92. doi:10.1016/j.jalz.2014.02.001

17. Harris Interactive (2011). What America thinks: MetLife Foundation Alzheimer's survey . https://www.metlife.com/assets/cao/foundation/alzheimers-2011.pdf 
18. Cantegreil-Kallen, I., \& Pin, S. (2012). Fear of Alzheimer's disease in the French population: Impact of age and proximity to the disease. International Psychogeriatrics, 24, 108-116. doi:10.1017/S1041610211001529

19. Bystad M, Gronli O, Lilleeggen C, Aslaksen M (2016). Fear of diseases among people over 50 years of age: A survey. psykologisk.no/sp/2016/12/e19/

20. Hayslip Jr, B. (2013). Fear of Alzheimer's disease in Middle to Late Adulthood: A Two Year Investigation of Change Versus Stability (Doctoral dissertation, University of North Texas).

21. Alzheimer's disease International (2015). "World Alzheimer Report 2015," in The Global Impact of Dementia: An Analysis of Prevalence, Incidence, Cost and Trends. Available online at: https://www.alz.co.uk/research/world-report-2015 (Accessed Aug 18, 2017).

22. Scerri, A., \& Scerri, C. (2017). Training older adults about Alzheimer's diseaseimpact on knowledge and fear. Educational Gerontology, 43(3), 117-127. http://dx.doi.org/10.1080/03601277.2016.1266445.

23. Folstien, M. (1999). Mini-Mental State, a practical methodfor grading the cognitive state of patients for the clinician inclinical Gerontological Nursing: A Guide to Advanced Practice.2nd.London: WB Saunders company.

24. Elokl, M. (2008). Prevalence of Alzheimer disease andother types of dementia in Egyptian elderly. Thesis, MSc, Ain Shams: University of Ain Shams, Faculty of medicine.

25. Abd El Moniem, M. (2012). Comparative study of the effect of three types of restorative Nursing Interventions on the health-related functional status of geriatric patients with Parkinson's disease. Unpublished doctorate thesis, Alexandria: university of Alexandria, Faculty of Nursing

26. Idler, E.L., Angel, R.J., (1990). Self-Rated health and mortality in the NHANESIEpidemiologic follow-up Study. American Jornal of Public Health 80(4),446452.https://dx.doi.org/10.2105\%2Fajph.80.4.446.

27. Carpenter BD, Balsis S, Otilingam PG, Hanson PK, Gatz M (2009). The Alzheimer's disease Knowledge Scale: development and psychometric properties. Gerontologist; 49(2):236-47 .

28. El-Zeftawy A, Sabra A (2018). Effect of Psycho-educational Program about Alzheimer's disease on knowledge, healthy lifestyle, depression, and burden of caregivers of Alzheimer's patients. International Journal of Novel Research in Healthcare and Nursing Vol. 5, Issue 2, pp: (266-282), Month: May - August 2018, Available at: www.noveltyjournals.com .

29. French, S. L., Floyd, M., Wilkins, S., \& Osato, S. (2012). The fear of Alzheimer's disease scale: A new measure designed to assess anticipatory dementia in older adults. International journal of geriatric psychiatry, 27(5), 521-528: doi:10.1002/gps.v27.5

30. Hebert LE, Weuve J, Scherr PA, Evans DA. (2010). Alzheimer disease in the UnitedStates (2010-2050) estimated using the 2010 Census. Neurology. 2013; 80(19):1778-83. 
31. Annear M, Toye C, Eccleston C et al. (2015). Dementia Knowledge Assessment Scale: Development and preliminary psychometric properties. J Am Geriatr Soc;63:2375-2381

32. Alhazzani, A. A, Alqahtani, A. M., Alqahtani, M. S., Alahmari, T. M., \& Zarbah, A. A. (2020). Public awareness, knowledge, and attitude toward Alzheimer's disease in Aseer region, Saudi Arabia. The Egyptian Journal of Neurology, Psychiatry and Neurosurgery, 56(1), 1-7.

33. Carpenter, B. D., Zoller, S. M., Balsis, S., Otilingam, P. G., \& Gatz, M. (2011). Demographic and contextual factors related to knowledge about Alzheimer's disease. American Journal of Alzheimer's Disease and other Dementias, 26(2), 121-126.

34. Formosa, M. (2012). Education and older adults at the University of the Third Age. Educational Gerontology, 38(2), 114-126.

35. El-masry, R., Elwasify, M., \& Khafagy, M. (2018). Adaptation and Reliability of the Arabic Version of Alzheimer's Disease Knowledge Scale (ADKS) among sample of middle aged and elderly Egyptians attending outpatient clinics in Mansoura. The Egyptian Journal of Community Medicine, 36, 59-69. 24, 108-116. doi: 10.1017/S1041610211001529.

36. Hamza, S. A., Mousa, S. M., Abdul-Rahman, S. A., \& Abd Elaziz, K. M. (2014). Evaluating knowledge of Dementia and Alzheimer's Disease among Egyptians. EJGG, 1(2), 1-11.

37. Sun ,F., Gao,X., \& Coon, D. W. (2013). Perceived threat of Alzheimer's disease among Chinese American older adults: the role of Alzheimer's disease literacy. The Journals of Gerontology Series B: Psychological Sciences and Social Sciences, 70(2), 245-25.

38. Cutler, S. J., \& Brăgaru, C. (2015). Long-term and short-term predictors of worries aboutgetting Alzheimer's disease. European Journal of Ageing,12(4),341-351.

39. Roberts, J. S., McLaughlin, S. J., \& Connell, C. M. (2014). Public beliefs and knowledge about risk and protective factors for Alzheimer's disease. Alzheimer's \& Dementia, 10(5), S381-S389.

40. Vrinten, C., van Jaarsveld, C. H., Waller, J., von Wagner, C., \& Wardle, J. (2014). The structure and demographic correlates of cancer fear. BMC Cancer, 14, 597. doi:10.1186/1471-2407-14-597.

41. Howell, J. C., Soyinka, O., Parker, M., Jarrett, T. L., Roberts, D. L., Dorbin, C. D., \& Hu, W. T. (2016). Knowledge and attitudes in Alzheimer's disease in a cohort of older African Americans and Caucasians. American Journal of Alzheimer's Disease \& Other Dementias®, 31(4), 361-367. doi:10.1177/1533317515619037.

42. Patidar, K., \& Patel, N. (2019). A Study to assess the Effectiveness of Structured Teaching Programme (STP) on Knowledge regarding risk factors and prevention of Peptic ulcer among the middle age Population in selected urban area at Mehsana City. Asian Journal of Nursing Education and Research, 9(3), 370-372.

43. Friedland R, Murrary S, Obisesan TO, Glick MA, GatzM, Farlow MR et al. (2011). Evaluation of Alzhiemer's disease education programme in the African American community. Proceedings of $26^{\text {th }}$ international conference of Alzhimer's disease:2011 Mar; Toronto, Canada 
44. Officer, A., Schneiders, M. L., Wu, D., Nash, P., \& Thiagarajan, J. A. (2016). Valuing older people: Time for a global campaign to combat ageism. Bulletin of the World Health Organization, 94, 710-710A. doi:10.2471/BLT.16.184960.

45. Levy, B. R., Ferucci, L., Zonderman, A. B., Slade, M. D., Tronocoso, J., \& Resnick, S. M. (2016). A culture-brain link: Negative age stereotypes predict Alzheimer's disease biomarkers. Psychology and Aging, 31, 82-88. doi:10.1037/pag0000062.

46. Kessler, E. M., Bowen, C. E., Baer, M., Froelich, L., \& Wahl, H. W. (2012). Dementia worry: A psychological examination of an unexplored phenomenon. European Journal of Ageing, 9(4), 275-284. doi:10.1007/s10433-012-0242-8.

47. Alzheimer Europe (2011). Harvard school of public health. Five-country Alzheimer's disease survey. Retrieved from http://www.alzheimereurope.org/Research/Value-of-Knowing

48. Nelissen, S., Beullens, K., Lemal, M., \& Van den Bulck, J. (2015). Fear of cancer is associated with cancer information seeking, scanning and avoiding: A crosssectional study among cancer diagnosed and non-diagnosed individuals. Health Information \& Libraries Journal, 32(2), 107-119. doi:10.1111/hir.2015.32.issue-2. 